South African Journal of Geomatics, Vol. 5, No. 1, February 2016

\title{
The identification and remote detection of alien invasive plants in commercial forests: An Overview
}

\author{
Kabir Peerbhay* Onisimo Mutanga and Riyad Ismail \\ University of KwaZulu-Natal, School of Agricultural, Earth and Environmental Sciences, Discipline of Geography, \\ P/Bag X01, Scottsville 3209, Pietermaritzburg, South Africa. \\ *Corresponding author Peerbhaykabir@gmail.com Tel: +27 738552166; fax: +27 332605344
}

DOI: $\underline{\text { http://dx.doi.org/10.4314/sajg.v5i1.4 }}$

\begin{abstract}
Invasive alien plants are responsible for extensive economic and ecological damage in forest plantations. They have the ability to aggressively manipulate essential ecosystem structural and functional processes. Alterations in these processes can have detrimental effects on the growth and productivity of forest species and ultimately impact on the quality and quantity of forest wood material. Using direct sampling field-based methods or visual estimations have generally expressed moderate success owing to the logistical and timely impracticalities. Alternatively, remote sensing techniques offer a synoptic rapid approach for detecting and mapping weeds affecting plantation forest environments. This paper reviews remote sensing techniques that have been used in detecting the occurrence of weeds and the implications for detecting $S$. mauritianum (bugweed); one of the most notorious alien plant invaders to affect southern Africa. Gaining early control of these alien plant invasions would reduce the impacts that may permanently alter our forested ecosystems, contributing to its successful eradication and promoting sustainable forest management practices. Furthermore, the review highlights the difficulties and opportunities that are associated with weed identification using remote sensing and future directions of research are also proposed.
\end{abstract}




\section{Background}

Invasions by alien plants have extensive economic and ecological effects on their introduced environments and are recognised as one of the most profound causes to biodiversity loss (Richardson and van Wilgen, 2004). The escalating rate of spread of invasive plants is responsible for homogenising biodiversity and may be considered a significant component of species extinction (Joshi et al., 2004). Plant invasions can also contribute significantly to changes in the structure and functioning of ecosystems and have the capability to erode natural capital (van Wilgen et al., 2012). They effectively capture available natural resources, survive and reproduce unaided across landscapes (van Wilgen et al., 2001). Plant invaders indirectly affect native plant communities and invoke ecosystem changes that can alter the quantity and quality of plant substrates, soil properties, the microclimate, water relations, density and height of vegetation (Ehrenfeld et al., 2001). These insidious and resilient qualities of plant invaders are not only responsible for compromising forest health and ecosystem goods and services, but also threaten economic productivity, both in man-made and natural ecosystems (Joshi et al., 2004, Richardson and van Wilgen, 2004, Chornesky et al., 2005).

Alien plant invasions within managed plantations may have detrimental effects on the growth and productivity of commercial forest species (Campbell and van Staden, 1990, Little et al., 1997). These actively managed environments are not immune to plant invasions and have rather become prime invasion sinks for infestation (van Wilgen et al., 2008). Firstly, forestry operations often facilitate invasions through poor weed control measures in nurseries or by transporting invader seeds when utilising field machinery (Le Maitre et al., 2004). Secondly, tree felling, logging and planting are common silvicultural practices that aggravate weed densities and promote weed distribution through disturbances (Mullerova et al., 2005). Finally, roads used to service forest compartments represent pathways that introduce alien species from which some spread from the edges into forest interiors (Pauchard and Alaback, 2004). Given the potential threat alien plants portray, conservationists, scientists and commercial organisations have to develop and adopt mitigation approaches to ensure sustainable forestry management (Chornesky et al., 2005). These include environmental certifications which compel forest companies to limit 
the distribution of alien plant invader propagules in support of controlling the spread of alien plant species (Le Maitre et al., 2004).

Despite evidence suggesting that commercial forest ecosystems are prime environments for the establishment of invasive alien plants (IAPs) and the need to protect these valuable and vulnerable resources (Campbell and van Staden, 1990, Little et al., 1997, Chornesky et al., 2005), very little attention has been paid to the detection and mapping of weeds in these complex ecosystems. In this context, one significant alien plant invader commonly occurring within commercial forests as well as provoking serious economic and ecologic concerns is Solanum mauritianum (Campbell and van Staden, 1990, Little et al., 1997).

Indigenous to South America, S. mauritianum, commonly known as bugweed (Fig. 1), has become one of the most notorious alien invasive plant species to affect southern Africa (Olckers and Borea, 2009). It is recognised as one of the sixth most aggressive, opportunistic and extremely resilient plant invaders in the region. Bugweed is an evergreen, noxious, branched shrub, varying between $2 \mathrm{~m}$ to $10 \mathrm{~m}$ in height with grey-green oval shaped leaves. The plant has a lifespan of up to thirty years and is a major constituent of agricultural land, forestry plantations, water courses and disturbed environments (Copeland and Wharton, 2006, Olckers and Borea, 2009). Bugweed has earned a classification of a category one 'transformer' weed (Jordaan and Downs, 2012) indicating that extensive stands are able to dominate and replace canopy or subcanopy layers of forest ecosystems (Witkowski and Garner, 2008, Olckers, 2011). Bugweed invasions may substantially propagate with changes in regional and global climate (van Wilgen et al., 2008). Increased nitrogen deposition, increased levels of atmospheric carbon dioxide, elevated temperatures and variability in rainfall, are all consequences of climate change that favour the establishment of the weed (Huang and Asner, 2009). Frugivorous birds also promote high levels of seedling recruitment across the landscape, making bugweed a successful plant invader (Jordaan and Downs, 2012). The weed has the ability to self-pollinate, with a rapid reproductive output and produces berries throughout the year. Since the berries have a greater nutritional status than many indigenous fruits, its success escalates as many bird species' diets shift with the availability of food resources (Jordaan and Downs, 2012). Each berry contains approximately 150 to 250 seeds of which $98 \%$ are viable (van den Bosch et al., 2004) . 


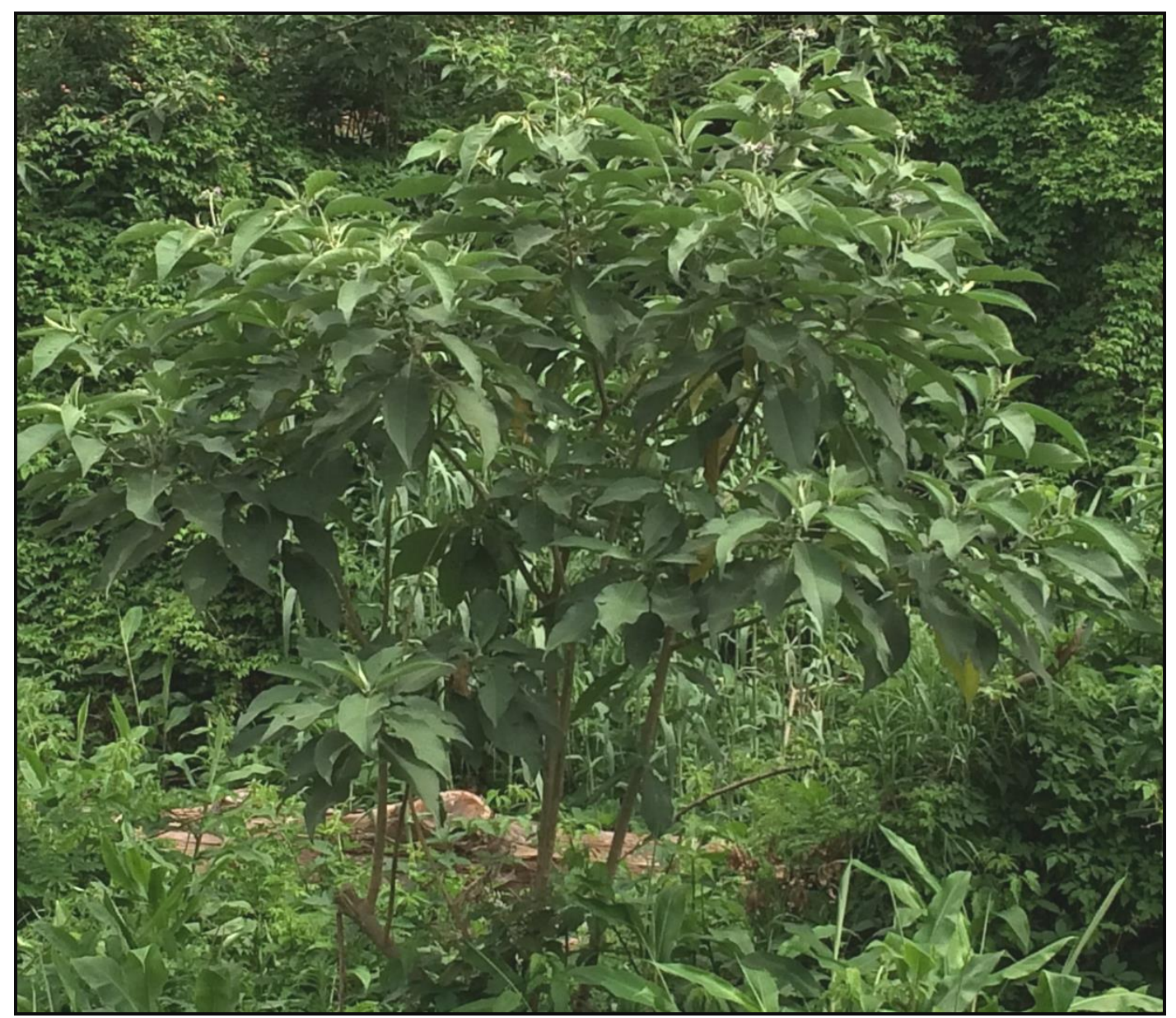

Figure 1. The alien invasive plant, $S$. mauritianum, located within the riparian zone of the forest.

From an economic and ecological standpoint, it is absolutely necessary to manage the adverse effects of bugweed in plantation forests. Gaining early control of these alien infestations could reduce the impacts that may permanently alter the structure and function of our forested ecosystems and contribute to the successful prevention and eradication of the weed. With the potential of climate change to significantly exacerbate the problems associated with IAPs, modelling the characteristics, spatial extent and severity of infestations will become unavoidable. While traditional efforts of estimating alien invasive plant cover rely on the generation of costly ground-based survey methods, which are not only technically and logistically impractical (Lawrence et al., 2006), remote sensing technologies offer a rapid alternative by providing a source of obtaining data over broad spatial extents (Kerr and Ostrovsky, 2003, Andrew and Ustin, 2008). Many studies have used remote sensing to detect and monitor noxious alien plant 
invasions in natural and semi-natural ecosystems (Everitt et al., 1995, Ustin et al., 2002, Joshi et al., 2004, Everitt et al., 2005, Mundt et al., 2005, Andrew and Ustin, 2009). However, to the best of our knowledge, research has been limited (Atkinson et al., 2014, Peerbhay et al., 2015) with regards to identifying and mapping IAPs in commercial forest ecosystems.

Currently, there are no specific methodologies of detecting or mapping alien plants in commercial forests. Therefore, this review aimed to discuss the potential of identifying and mapping the occurrence of bugweed using remote sensing technologies. Firstly, the difficulties experienced when locating and removing IAPs in commercial forest plantations were assessed. Thereafter, the application of remotely sensed techniques to detect IAP's using direct and indirect approaches were reviewed; whilst generating the necessary knowledge for mapping bugweed within commercial forestry. The utility of aerial, multispectral and hyperspectral remote sensing for this application are also discussed. Finally, the challenges associated with using remotely sensed technologies are considered and possible solutions suggested for guiding the success of future operational interventions for locating and mapping bugweed in commercial forests.

\section{Mitigation measures against alien plant invaders}

One of the most common management tools used to control alien plant invasions in commercial forests is the use of herbicides. However, weeds are becoming increasingly resistant towards this general execution (Holzmueller and Jose, 2009). The introduction of several chemical and mechanical control methods has also experienced difficulties owing to the expenses associated with such techniques and the spatial extent of infestations. Although biological control programs such as using natural enemies to control the spread of weeds has shown the most potential, to date, their overall impact on controlling IAPs remains insufficient (Olckers and Borea, 2009). Most of the bio-control agents are leaf feeders and usually extend beyond their target plants, becoming pests to cultivated and other plants (Olckers, 2004). Alien plants are often able to persist as invasive despite attempts to eliminate them. Sometimes weed control itself may contribute to the prolific dispersal of seedlings. Most plant invaders also recover rapidly after clearing due to either re-sprouting or germination from dense seed banks within the soil (Witkowski and Garner, 2008). These multiple strategies used to gain dominance in their 
introduced habitats have made efforts to control them extremely difficult (Holzmueller and Jose, 2009).

In response to the widespread, fast growing and constant threat which plant invaders may present in forest ecosystems, forest managers require an integrated management system combining detection, mapping and monitoring that is operationally accurate and cost effective (Lawrence $e t$ al., 2006). Since weed infestations are not distributed evenly across infected areas, a key requirement for their effective management is to be able to detect and delineate the spatial extent and the severity of infestation (Ustin et al., 2002). Additionally, a precise weed detection system is a prerequisite for a better weed management strategy and effective implementation (Goel et $a l ., 2002)$. Remote sensing can serve as a viable alternative to traditional field-based methods for obtaining information on weeds in commercial forests. The technology can be used for the accurate and timely detection of weed locations and their distributions and intensities.

\section{Assessing the potential of remotely sensed data for alien plant detection}

The most common remote sensing approach for detecting weeds is to utilise high spatial resolution imagery such as aerial photography (Huang and Asner, 2009). Everitt et al. (1995) for example, conducted studies using aerial photographs to monitor the infestation of one Eurasian (Euphorbia esula) and one Asian (Tamarix chinensis) plant. Wavelengths in the visible (400 nm - $700 \mathrm{~nm}$ ) portion of the electromagnetic spectrum and geographic information system (GIS) analysis successfully mapped the infestations. Similarly, Anderson et al. (1996) accurately mapped the occurrence of leafy spurge by combining topographical features (aspect, slope and watershed basin) for a more in-depth analysis. Mullerova et al. (2005) used time series aerial panchromatic camera (WILD 328) data in conjunction with colour infrared photographs to monitor the Heracleum mantegazzianum (giant hogweed) invasion in the Czech Republic. Results were analysed using an analysis of covariance (ANCOVA), multiple regression and path analysis. Multiple photographs showed that the alien plant invader was easily detected due to its flowering and fruiting. Recently, high spatial resolution aerial photographs were also used to identify Fallopia japonica (Japanese knotweed) with an object-based classification approach (Jones et al., 2011). While the timing of the acquisition of data is crucial for aerial photographic analysis, these early methodologies to visually observe weeds are limited to small spatial extents (Mundt et al., 2005). Aerial photographs also only work best when the weeds have unique 
growth patterns distinct from surrounding vegetation. Therefore, a more robust approach is to use multispectral remote sensing (Huang and Asner, 2009).

Multispectral remote sensing ( $\leq 8$ bands) improves on aerial photography by recording spectral information in a number of different wavelengths across the electromagnetic spectrum (Mundt $e t$ al., 2005; Peerbhay et al., 2014b). For example, Fuller (2005) mapped the invasive Melaleuca quinquenervia (paperbark) tree native to Australia using IKONOS imagery with a spatial resolution of $4 \mathrm{~m}$. The study employed a back-propagation neural network (NN) classifier coupled with landscape fragmentation analysis and produced a highly distinctive pattern (overall accuracy $>85 \%$ ) from woody plants. Laba et al. (2008) estimated the presence of three alien plants, Lythrum salicaria (purple loosestrife), Phragmites australis (common reed) and Trapa natans (water chestnut) in a diverse wetland environment using high resolution Quickbird imagery $(2.4 \mathrm{~m})$. A maximum likelihood classifier demonstrated that the finer spatial resolution was a reliable data source for alien plant detection (overall accuracy $\geq 65 \%$ ). Recently, Somodi et al. (2012) combined Landsat ETM (30 m), orthophotography (0.5 m and 0.25 m) and GIS layers to detect Robinia pseudacacia (black locust). Digital orthophotos taken during the flowering stages provided the best data source for recognising the tree species.

Although multispectral remote sensing has the capability of detecting and mapping alien plants, the weeds are often obscured in a backdrop of natural vegetation making it difficult to detect (Mundt et al., 2005). Multispectral data may therefore only be effective to observe large weed stands and patches whose identification depends heavily on the phenological period during which the images are acquired (Huang and Asner, 2009). For example, Carson et al. (1995) were unsuccessful in mapping Hieracium pratense (yellow hawkweed) at species level using $30 \mathrm{~m}$ Landsat TM and $20 \mathrm{~m}$ SPOT data, unless the species stands were large enough (>20\% cover). Fuller (2005) was unsuccessful in identifying the invasive paperbark tree at low cover $(<50 \%$ cover) using $4 \mathrm{~m}$ resolution IKONOS multispectral wavelengths. In addition, the spectral similarity in reflectance between weeds and surrounding vegetation create difficulties when using multispectral analysis (Asner et al., 2008a). Alternatively, hyperspectral remote sensing has become more advantageous owing to the improved spectral resolution for mapping IAP's (Glenn et al., 2005). 
Hyperspectral data capture information from hundreds of narrow wavebands, providing a full spectral curve for each pixel (Peerbhay et al., 2013). Subsequently, the main advantage associated with hyperspectral data is that they provide detailed spectral profiles that can distinguish native from non-native plants and that the most significant spectral regions in detecting the species of interest can be analysed (Huang and Asner, 2009). Many studies have used hyperspectral remote sensing to detect alien plants (Ustin et al., 2002, Williams and Hunt, 2002, Glenn et al., 2005, Mundt et al., 2005, Asner et al., 2006, Asner et al., 2008a, Asner et al., 2008b, Peerbhay et al., 2014a, Peerbhay et al., 2015). Williams and Hunt (2002) for example, successfully mapped European Euphorbia esula (leafy spurge) utilising AVIRIS hyperspectral data. They applied a specialised spectral mixture analysis to improve the spectral recognition of the species. The early stages of leafy spurge were also mapped using high resolution HyMap data $(3.5 \mathrm{~m}$ ) with accuracies greater than $84 \%$ (Glenn et al., 2005). Ustin et al. (2002) used $4 \mathrm{~m}$ AVIRIS data to detect and map several alien invasive plant species including Carpobrotus edulis (iceplant), Cordateria jubata (jubata grass), Foeniculum vulgare (fennel) and Arundo donax (giant reed) in mixed chaparral and riparian ecosystems. While several classification methods produced successful results, maximum likelihood classifier methods performed better than unsupervised methods or vegetation indices for mapping the plant invaders. For the mapping of iceplant density, minimum noise fraction (MNF) (55.2\%) performance was superior to that of band ratios $(44 \%)$ or continuum removal analysis $(39 \%)$.

Mundt et al. (2005) discriminated Cardaria draba (hoary cress) using different hyperspectral processing parameters and classification algorithms. The most robust approach utilised MNF transformed reflectance data and resulted in producers, users and overall accuracies of $82 \%, 79 \%$ and $86 \%$, respectively. Lass et al. (2005) detected spotted Centaurea maculosa (knapweed) and Gypsophila paniculata (baby's breath) infestations in shrub/grassland using a charged couple device (CCD) sensing in the $415 \mathrm{~nm}-953 \mathrm{~nm}$ spectral range with a spatial resolution of $2 \mathrm{~m}$. A spectral angel mapper (SAM) classifier was used to classify images over a two year period and produced an overall site detection average of $67 \%$ for knapweed and $83.5 \%$ for baby's breath. In a previous study utilising a hyperspectral image spectrometer (440 - $2543 \mathrm{~nm})$, Lass et al. (2002) showed that knapweed was detectable using a SAM classifier and a spatial resolution of $5 \mathrm{~m}$. Spotted knapweed was also mapped with leafy spurge using the Probe-1 sensor and Breiman 
Cutler's random forest algorithm to produce classification accuracies of $84 \%$ and $86 \%$ respectively (Lawrence et al., 2006).

Recently, in a tree species application using AISA Eagle hyperspectral data (393 nm - $272 \mathrm{~nm}$ ) and partial least squares discriminant analysis (PLS-DA), Peerbhay et al. (2014) demonstrated the capability of separating bugweed from a variety of forest species (67\%). Atkinson et al. (2014), however, showed impressive classification accuracies when focusing on mapping bugweed occurring only within Pinus patula compartments (93\%). The study utilized band reduction techniques and support vector machines (SVM). Nonetheless, using a novel unsupervised RF approach and AISA Eagle data, Peerbhay et al. (2015) provided a semiautomated mapping accuracy of $88.96 \%$ when detecting bugweed as an anomaly within Pinus Patula stands.

While the use of hyperspectral sensors have become more advantageous owing to the wealth of spectral information for species level detection (Andrew and Ustin, 2008), the mapping of weeds based on their structural, biochemical and physiological characteristics were also exploited (Asner et al., 2008a, Asner et al., 2008b). In addition, certain studies have also used hyperspectral information in successfully mapping the cover and abundance of IAPs (Table 1). 
Table 1. Hyperspectral remote sensing studies related to the structural, physiological and spatial characteristics of invasive plants.

\begin{tabular}{|c|c|c|c|c|c|}
\hline Species & Sensor & Wavelengths & Data analysis & Overall results & Reference \\
\hline $\begin{array}{l}\text {-Myrica fava } \\
\text {-Native Metrosideros } \\
\text { polymorpha }\end{array}$ & $\begin{array}{l}\text { Hyperion time series } \\
\qquad(30 \mathrm{~m})\end{array}$ & $400-2500$ & $\begin{array}{l}\text { - Field measurements (LAI, foliar } \\
\text { chemistry analysis, leaf physiology) } \\
\text { - Hyperspectral indices (LAI, PRI, CRI, } \\
\text { NDVI, CWR) } \\
\text { - Climate inventory } \\
\text { (Temperature, rainfall, relative humidity, } \\
\text { canopy vapor pressure deficit) }\end{array}$ & $\begin{array}{c}\text { Myrica growth rates were } \\
16-44 \% \text { higher than native } \\
\text { metrosideros and thrived } \\
\text { in bioclimatic stressful } \\
\text { periods }\end{array}$ & $\begin{array}{c}\text { Asner et al. } \\
2006\end{array}$ \\
\hline $\begin{array}{l}\text { - Falcataria moluccana } \\
\text { - Fraxinus uhdei } \\
\text { - Hedychium } \\
\text { gardnerianum } \\
\text { - Morella faya } \\
\text { - Psidium cattleianum } \\
\end{array}$ & $\begin{array}{l}\text { Carnegie Airborne } \\
\text { Observatory } \\
(0.5 \mathrm{~m} \text { to } 2.5 \mathrm{~m})\end{array}$ & $367-2510$ & $\begin{array}{l}\text { - Field based transects and plot scale } \\
\text { measurements } \\
\text { - LAI }\end{array}$ & $\begin{array}{l}\text { Field validation tests } \\
\text { yielded }<7 \% \text { error }\end{array}$ & $\begin{array}{c}\text { Asner et al. } \\
\text { 2008a }\end{array}$ \\
\hline $\begin{array}{l}\text { - Ficus microcarpa } \\
\text { - Grevillea robusta } \\
\text { - Macaranga mappa } \\
\text { - Melastoma Candidum } \\
\text { - Psidium cattleianum } \\
\text { - Schefflera actinophylla } \\
\text { - Schinus molle } \\
\text { - Spathodea } \\
\text { campanulata } \\
\text { - Tibouchina granulosa } \\
\text { - Trema orientalis } \\
\text { - Falcataria moluccana } \\
\text { - Morella faya } \\
\end{array}$ & $\begin{array}{l}\text { AVIRIS } \\
(3 \mathrm{~m})\end{array}$ & $\begin{array}{c}400-700 \\
1125-2500\end{array}$ & $\begin{array}{l}\text { - Field leaf samples from tree crowns } \\
\text { - Leaf pigment (chlorophyll, carotenoids) } \\
\text { - nutrients (N, P) } \\
\text { - Structural properties (specific leaf area; } \\
\text { SLA) } \\
\text { - Partial least squares regression (PLS) }\end{array}$ & $\begin{array}{l}\mathrm{p} \text {-values ranged from } 0.01 \\
\text { to } 0.05 \text { when examining } \\
\text { the spectral differences } \\
\text { between highly invasive } \\
\text { and other native species }\end{array}$ & $\begin{array}{c}\text { Asner et al. } \\
\text { 2008b }\end{array}$ \\
\hline - Centaurea maculosa & $\begin{array}{l}\text { Image spectrometer } \\
\qquad(5 \mathrm{~m})\end{array}$ & $440-2543$ & $\begin{array}{l}\text { - Field data points } \\
\text { - Spectral signature development } \\
\text { - Spectral angel mapper (SAM) } \\
\text { classification }\end{array}$ & $\begin{array}{c}99 \% \text { for } \\
1 \%-40 \% \text { cover }\end{array}$ & $\begin{array}{l}\text { Lass et al. } \\
\quad 2002\end{array}$ \\
\hline $\begin{array}{l}\text { - Gypsophila paniculata } \\
\text { - Centaurea maculosa }\end{array}$ & $\begin{array}{l}\text { Charged couple device } \\
\qquad(2 \mathrm{~m})\end{array}$ & $415-953$ & $\begin{array}{l}\text { - Spectral reflectance training curves } \\
\text { - Spectral angel mapper (SAM) } \\
\text { classification } \\
\text { - Field validation }\end{array}$ & $\begin{array}{l}83.5 \% \\
67 \%\end{array}$ & $\begin{array}{l}\text { Lass et al. } \\
\quad 2005\end{array}$ \\
\hline
\end{tabular}


Since the capabilities of utilising remote sensing for the detection and mapping of weeds have been documented, the potential to exploit the technology for accurately mapping the unique spectral signatures of bugweed is also recognisable. From an operational perspective, the accurate mapping of weeds in commercial forests requires techniques that are viable and relatively cost effective. Therefore, the limited, yet encouraging results utilising multispectral information provide sufficient evidence to investigate the capability of the new generation of multispectral sensors. These high spatial resolution commercial satellite systems (e.g. WorldView-2, RapidEye and GeoEye) enable detailed observations in the visible to nearinfrared range and offer new opportunities for detecting and mapping weeds using space borne platforms.

Furthermore, the potential exists to exploit the effectiveness of readily accessible and available data such as the use of synthetic aperture radar (SAR) for detecting and mapping IAPs. SAR data is captured using an active sensor and can provide information related to the difference in structure and density between vegetation species (Bourgeau-Chavez et al., 2012; Ghulam et al., 2014). Long frequency signals such as the P-band and L-band, have the capability to penetrate the forest canopy to reveal structural information beneath, while short frequency signals such as the C-band is suitable for mapping at the canopy surface. Such information can be complementary when combined with passive optical imagery for mapping IAPs in complex forest environments (Ghulam et al., 2014), while proving access to cost effective remotely sensing data over broader extents. Nonetheless, only a few studies have investigated the potential use of SAR for alien plant detection (Bourgeau-Chavez et al., 2009; BourgeauChavez et al., 2012; Ghulam et al., 2014). For instance, using the L-band of the ALOS PALSAR sensor, Bourgeau-Chavez et al., (2009) mapped stands of invasive Phragmites (common reed) with better accuracy than airborne hyperspectral AVIRIS data. Subsequently, the effectiveness of multi-season L-band from ALOS POLSAR was demonstrated in accurately mapping the distribution of Phragmites over a large area (Bourgeau-Chavez et al., 2012). Finally, Ghulam et al., (2014) combined SAR data (PALSAR and Radasat-2) along with spectral information (Hyperion, Landsat, IKONOS) and tree height (GeoEye-1 stereo) to accurately characterize the spatial extent of Psidium cattleianum (Guava), Aframomum angustifolium (Madagascar cardamom) and Rubus moluccanus (Molucca raspberry). The study permits the use of L-band SAR for the detailed mapping of invasive species while the C-band saturating at increased forest height and density. 


\section{Understory and mixed canopy species}

Many IAPs, including bugweed, grow as subtle understory or mid-level canopy vegetation (Joshi et al., 2006). Therefore they do not dominate the canopy making it difficult for direct remote detection (Asner et al., 2008a). Although both spatial and spectral resolutions are primary determinants of the accuracy when mapping IAPs, higher resolutions would not necessarily ensure that weed infestations in forest environments will be measurable (Mundt $e t$ al., 2005). Researchers, however, adopt alternate methods such as using conventional image classification techniques and expert systems. Expert systems utilise ancillary data and can infer the most probable characteristics of a target weed species in a specific location (Masocha and Skidmore, 2011). They may be implemented in a GIS environment and often yield better results than using single classification methods. Many studies have been successful in utilising GIS expert systems for mapping understory vegetation (Schmidt et al., 2004, Vaiphasa et al., 2006, Wang et al., 2009). For example, topographical information was combined with hyperspectral imagery to map 19 vegetation types in a salt marsh environment using a hybrid SAM and an expert system (Schmidt et al., 2004). Vaiphasa et al. (2006) used soil $\mathrm{pH}$ data together with ASTER imagery to discriminate mangrove species using a hybrid maximum likelihood classification algorithm and an expert system. Wang et al. (2009) combined an ANN with an expert system and mapped understory bamboo species. Recently, Masocha and Skidmore (2011) combined habitat and terrain position data and mapped the cover of invasive Lantana camara (cherrypie) using single and hybrid SVM and NN classification methods. In this regard, GIS expert systems may therefore be used in combination with remotely sensed data to assist in mapping understory IAPs such as bugweed within plantation forestry environments.

Indirect mapping approaches may also assist in mapping the distribution of invasive weeds by using information related to the ecological relationship between species and the environment (Joshi et al., 2004). For example, Joshi et al. (2006) estimated canopy gaps to predict understory Chromolaena odorata (siam weed) infestations using Landsat ETM+ data. Utilising an ANN, they successfully predicted forest canopy density and light intensity reaching the understory and mapped $64 \%$ of variation in $C$. odorata cover. Other studies used the phenological differences between the canopy overstory and understory species. For instance, Resasco et al. (2007) and Wilfong et al. (2009) successfully detected Lonicera maackii (bush honeysuckle), in the understory of deciduous forests stands using Landsat imagery when the overstory trees were leafless. Similarly, Groeneveld and Watson (2008) 
used the Landsat TM near-infrared band to map Tamarix ramosissima (saltcedar) during winter, when the plant branches were leafless. Landsat imagery was also used to map the distribution of two understory bamboo species by exploiting the phenological difference between overstory trees and understory bamboos (Tuanmu et al., 2010). The success in mapping understory invasive plants from other vegetation covers therefore appears to be dependent on specific acquisition dates of satellite images. This may be further investigated to improve the detection of difficult weed species occurring in South Africa and within complex environments.

\section{Limitations of utilising remote sensing for alien plant detection}

As mentioned earlier, spatial and spectral information obtained from medium resolution sensors is insufficient when delineating or detecting IAPs. High spatial resolution remote sensing such as aerial photography, although being successful in mapping the distribution of certain plant invaders, may not be capable of distinguishing weeds that are obscured in a backdrop of vegetation. Using even the very high spatial resolution space-borne images may provide a challenge to discriminate such invasive plants at species level (Huang and Asner, 2009). Phenological variations which are significant in detecting plant invasions may not be distinct owing to the coarse spectral resolution of high spatial resolution sensors. On the one hand, utilising high spatial resolution data may be less feasible over large areas and can affect the overall mapping outcome. Utilising the high spectral resolution of hyperspectral remote sensing, on the other hand, may represent an oversampled dataset, which results in high data dimensionality and redundant wavebands that may be irrelevant for detecting the alien invasive plant species of interest. Apart from overwhelming data analysis methods that increase computational demands, spectral variations influenced by background effects such as soil characteristics and non-photosynthetic material could overwrite significant response signals of target invasive plants. It is therefore essential to invest in the development of accurate automated and semi-automated algorithms that are able to fully exploit the huge amount of information linked with remotely sensed datasets so as to address the spectral complexities when detecting IAP species for real-time monitoring and decision making.

\section{Summary and discussion}

Alien plants present a number of important ecological and economic problems despite attempts to control them. Therefore, the use of remote sensing for the detection of noxious 
weeds has become practical in a variety of ecosystem types. Aerial photography, although limited to small spatial extents and dependent on distinct spectral patterns of plant invaders; still provides a reliable method for mapping alien plants. The use of multispectral imagery has demonstrated success in mapping the distribution of plant invaders; however, the low spectral resolution limits the application of this technology. Imagery with higher spectral resolutions such as hyperspectral data therefore provides superior species discriminative capabilities for alien plant detection. In this review, the application of remote sensing techniques for detecting and mapping IAPs were investigated. Overall, remote sensing technologies have been successfully introduced to a variety of weed detection applications and in different environments. However, most of the studies using remote sensing were conducted in areas represented by relatively homogenous landscapes that were free from canopy species. Therefore, detecting, mapping and modelling plant invasions in commercial forest environments will still be a major challenge as many invasive plant species grow as understory vegetation. Bugweed, in particular, has the ability to dominate the understory as well as the ability to establish itself as extensive weed stands. This complexity makes it difficult to delineate complete invasions. However, the capability of remote sensing, integrated with expert knowledge and GIS, may enhance the recognition of the weed in commercial forests.

\section{Directions of future research}

The increase in satellite sensor technology will provide continuous opportunities for the application of remotely sensed data in mapping and modelling the distribution of invasive weeds. The advancement of the new generation of multispectral sensors (e.g., WorldView-2, RapidEye and GeoEye), with their very high spatial resolutions, has the potential to improve on the detection and mapping of alien species. Future research may also focus on utilising remote sensing technology such as light detection and ranging (LiDAR) which measures the distance between the sensor and target surface. LiDAR information can provide structural information on canopies, underlying vegetation and the terrain below (Asner et al., 2008b) and could be instrumental in recognising a greater variety of IAPs than previously detected. Similarly, the integration of spectral information with LiDAR and SAR instrument systems could improve the analysis of plant invader functional and structural properties and provide an accurate framework for mapping alien plants in commercial forest environments. In 
South African Journal of Geomatics, Vol. 5, No. 1, February 2016

addition, it would be interesting to investigate the utility of LiDAR or SAR within an unsupervised remote sensing weed detection application.

\section{Acknowledgements}

This study was carried out with the financial assistance from the Applied Centre for Climate and Earth Systems Science (ACCESS). We would like to thank Sappi forests-SA for allowing us the opportunity to carry out our study under excellent conditions.

\section{References}

Anderson, G., Everitt, J., Escobar, D., Spencer, N. and Andrascik, R. 1996. Mapping Leafy spurge (Euphorbia esula) infestations using aerial photography and geographic information systems. Geocarto International, 11(1): 81-89.

Andrew, M. E. and Ustin, S. L. 2008. The role of environmental context in mapping invasive plants with hyperspectral image data. Remote Sensing of Environment, 112(12): 4301-4317.

Andrew, M. E. and Ustin, S. L. 2009. Habitat suitability modelling of an invasive plant with advanced remote sensing data. Diversity and Distributions, 15(4): 627-640.

Asner, G. P., Hughes, R. F., Vitousek, P. M., Knapp, D. E., Kennedy-Bowdoin, T., Boardman, J., Martin, R. E., Eastwood, M. and Green, R. O. 2008a. Invasive plants transform the three-dimensional structure of rain forests. Proceedings of the National Academy of Sciences, 105(11): 4519-4523.

Asner, G. P., Jones, M. O., Martin, R. E., Knapp, D. E. and Hughes, R. F. 2008b. Remote sensing of native and invasive species in Hawaiian forests. Remote Sensing of Environment, 112(5): 1912-1926.

Asner, G. P., Martin, R. E., Carlson, K. M., Rascher, U. and Vitousek, P. M. 2006. Vegetation-climate interactions among native and invasive species in Hawaiian rainforest. Ecosystems, 9(7): 1106-1117.

Atkinson, J. T., Ismail, R. and Robertson, M. 2014. Mapping bugweed (Solanum mauritianum) infestations in pinus patula plantations using hyperspectral imagery and support vector machines. IEEE Journal of Selected Topics in Applied Earth Observation and Remote Sensing, 7(1): 17-28

Bourgeau-Chavez, L.L., Riordan, K., Powell, R.B., Miller, N., Nowels, M. 2009. Improving wetland characterization with multi-sensor, multi-temporal SAR and optical/infrared data fusion. In: Jedlovec, Gary (Ed.), Advances in Geoscience and Remote Sensing. InTech Publishers, India: 679-708.

Bourgeau-Chavez, L.L., Kowalski, K.P., Mazur, M.L.C., Scarbrough, K.A., Powell, R.B., Brooks, C.N., Huberty, B., Jenkins, L.K., Banda, E.C., Galbraith, D.M. and Laubach, Z.M. 2012. Mapping invasive Phragmites australis in the coastal Great Lakes with ALOS PALSAR satellite imagery for decision support. Journal of Great Lakes Research, 39: 65-77. 
Campbell, P. and van Staden, J. 1990. Utilisation of solasodine from fruits for long-term control of Solanum mauritianum. South African Forestry Journal, 155(1): 57-60.

Carson, H. W., Lass, L. W. and Callihan, R. H. 1995. Detection of yellow hawkweed (Hieracium pratense) with high resolution multispectral digital imagery. Weed Technology: 477-483.

Chornesky, E. A., Bartuska, A. M., Aplet, G. H., Britton, K. O., Cummings-Carlson, J., Davis, F. W., Eskow, J., Gordon, D. R., Gottschalk, K. W., Haack, R. A., Hansen, A. J., Mack, R. N., Rahel, F. J., Shannon, M. A., Wainger, L. A. and Wigley, T. B. 2005. Science priorities for reducing the threat of invasive species to sustainable forestry. BioScience, 55(4): 335-348.

Copeland, R. S. and Wharton, R. A. 2006. Year round production of pest ceratitis species (diptera: Tephritidae) in fruit of the invasive species solanum mauritianum in Kenya. Annals of the Entomological Society of America, 99(3): 530-535.

Ehrenfeld, J. G., Kourtev, P. and Huang, W. 2001. Changes in soil functions following invasions of exotic understory plants in deciduous forests. Ecological Applications, 11(5): 1287-1300.

Everitt, J. H., Anderson, G. L., Escobar, D. E., Davis, M. R., Spencer, N. R. and Andrascik, R. J. 1995. Use of remote sensing for detecting and mapping Leafy spurge (Euphorbia esula). Weed Technology, 9(3): 599-609.

Everitt, J. H., Yang, C. and Deloach, C. 2005. Remote sensing of Giant reed with quickbird satellite imagery. Journal of Aquatic Plant Management, 43: 81-85.

Fuller, D. O. 2005. Remote detection of invasive Melaleuca trees (melaleuca quinquenervia) in South Florida with multispectral IKONOS imagery. International Journal of Remote Sensing, 26(5): 1057-1063.

Ghulam, A., Porton, I. and Freeman, K. 2014. Detecting subcanopy invasive plant species in tropical rainforest by integrating optical and microwave (InSAR/PolInSAR) remote sensing data, and a decision tree algorithm. ISPRS Journal of Photogrammetry and Remote Sensing, 88: 174-192.

Glenn, N. F., Mundt, J. T., Weber, K. T., Prather, T. S., Lass, L. W. and Pettingill, J. 2005. Hyperspectral data processing for repeat detection of small infestations of Leafy spurge. Remote Sensing of Environment, 95(3): 399-412.

Goel, P., Prasher, S., Patel, R., Smith, D. and DiTommaso, A. 2002. Use of airborne multi-spectral imagery for weed detection in field crops. Transactions-American Society of Agricultural Engineers, 45(2): 443-450.

Groeneveld, D. P. and Watson, R. P. 2008. Near-infrared discrimination of leafless saltcedar in wintertime Landsat TM. International Journal of Remote Sensing, 29(12): 3577-3588.

Holzmueller, E. J. and Jose, S. 2009. Invasive plant conundrum: What makes the aliens so successful? Journal of Tropical Agriculture, 47(1-2): 18-29.

Huang, C.-Y. and Asner, G. 2009. Applications of remote sensing to alien invasive plant studies. Sensors, 9(6): 4869-4889.

Jones, D., Pike, S., Thomas, M. and Murphy, D. 2011. Object-based image analysis for detection of Japanese Knotweed s.l. taxa (Polygonaceae) in Wales (UK). Remote Sensing, 3(2): 319-342. 
Jordaan, L. A. and Downs, C. T. 2012. Comparison of germination rates and fruit traits of indigenous solanum giganteum and invasive solanum mauritianum in South Africa. South African Journal of Botany, 80(0): 13-20.

Joshi, C., De Leeuw, J., van Andel, J., Skidmore, A. K., Lekhak, H. D., van Duren, I. C. and Norbu, N. 2006. Indirect remote sensing of a cryptic forest understorey invasive species. Forest Ecology and Management, 225(1-3): 245-256.

Joshi, C., de Leeuw, J. and van Duren, I. C. 2004. Remote sensing and GIS applications for mapping and spatial modelling of invasive species. Proceedings of ISPRS.

Kerr, J. T. and Ostrovsky, M. 2003. From space to species: Ecological applications for remote sensing. Trends in Ecology and Evolution, 18(6): 299-305.

Laba, M., Downs, R., Smith, S., Welsh, S., Neider, C., White, S., Richmond, M., Philpot, W. and Baveye, P. 2008. Mapping invasive wetland plants in the hudson river national estuarine research reserve using quickbird satellite imagery. Remote Sensing of Environment, 112(1): 286-300.

Lass, L. W., Prather, T. S., Glenn, N. F., Weber, K. T., Mundt, J. T. and Pettingill, J. 2005. A review of remote sensing of invasive weeds and example of the early detection of spotted knapweed (centaurea maculosa) and babysbreath (gypsophila paniculata) with a hyperspectral sensor. Weed Science, 53(2): 242-251.

Lass, L. W., Thill, D. C., Shafii, B. and Prather, T. S. 2002. Detecting spotted knapweed (centaurea maculosa) with hyperspectral remote sensing technology 1. Weed Technology, 16(2): 426-432.

Lawrence, R. L., Wood, S. D. and Sheley, R. L. 2006. Mapping invasive plants using hyperspectral imagery and breiman cutler classifications (randomforest). Remote Sensing of Environment, 100(3): 356-362.

Le Maitre, D. C., Richardson, D. M. and Chapman, R. A. 2004. Alien plant invasions in South Africa: Driving forces and the human dimension. South African Journal of Science, 100: 103 -112.

Little, K., Kritzinger, J. and Maxfield, M. 1997. Some principles of vegetation management explained, University of KwaZulu-Natal. Pietermaritzburg

Masocha, M. and Skidmore, A. K. 2011. Integrating conventional classifiers with a GIS expert system to increase the accuracy of invasive species mapping. International Journal of Applied Earth Observation and Geoinformation, 13(3): 487-494.

Mullerova, J., Pyšek, P., JaroŠik, V. and Pergl, J. A. N. 2005. Aerial photographs as a tool for assessing the regional dynamics of the invasive plant species Heracleum mantegazzianum. Journal of Applied Ecology, 42(6): 1042-1053.

Mundt, J. T., Glenn, N. F., Weber, K. T., Prather, T. S., Lass, L. W. and Pettingill, J. 2005. Discrimination of hoary cress and determination of its detection limits via hyperspectral image processing and accuracy assessment techniques. Remote Sensing of Environment, 96(3-4): 509-517.

Olckers, T. 2004. Biology, host specificity and risk assessment of the leaf-mining flea beetle, Acallepitrix sp. nov., a candidate agent for the biological control of the invasive tree solanum mauritianum in south africa. BioControl, 49: 323-339. 
Olckers, T. 2011. Biological control of solanum mauritianum scop. (Solanaceae) in South Africa: Will perseverance pay off? African Entomology, 19(2): 416-426.

Olckers, T. and Borea, C. 2009. Assessing the risks of releasing a sap-sucking lace bug, gargaphia decoris, against the invasive tree solanum mauritianum in New Zealand. BioControl, 54(1): 143-154.

Pauchard, A. and Alaback, P. B. 2004. Influence of elevation, land use, and landscape context on patterns of alien plant invasions along roadsides in protected areas of south-central Chile. Conservation Biology, 18(1): 238-248.

Peerbhay, K. Y., Mutanga, O. and Ismail, R. 2013. Commercial tree species discrimination using airborne AISA eagle hyperspectral imagery and partial least squares discriminant analysis (PLS-DA) in KwaZulu-Natal, South Africa. ISPRS Journal of Photogrammetry and Remote Sensing, 79: 19-28.

Peerbhay, K. Y., Mutanga, O. and Ismail, R. 2014a. Does simultaneous variable selection and dimension reduction improve the classification of pinus forest species? Journal of Applied Remote Sensing, 8(1): 085194-085194.

Peerbhay, K. Y., Mutanga, O. and Ismail, R. 2014b. Investigating the capability of few strategically placed worldview-2 multispectral bands to discriminate forest species in KwaZulu-Natal, South Africa. IEEE Journal of Selected Topics in Applied Earth Observations and Remote Sensing, 7(1): 307-316.

Peerbhay, K. Y., Mutanga, O. and Ismail, R. 2015. Random forests unsupervised classification: The detection and mapping of solanum mauritianum infestations in plantation forestry using hyperspectral data. IEEE Journal of Selected Topics in Applied Earth Observation and Remote Sensing, 8(6): 3107 3122, DOI: 10.1109/JSTARS.2015.2396577.

Resasco, J., Hale, A. N., Henry, M. C. and Gorchov, D. L. 2007. Detecting an invasive shrub in a deciduous forest understory using late-fall Landsat sensor imagery. International Journal of Remote Sensing, 28(16): 3739-3745.

Richardson, D. M. and van Wilgen, B. W. 2004. Invasive alien plants in South Africa: How well do we understand the ecological impacts? South African Journal of Science, 100: 45-52

Schmidt, K., Skidmore, A., Kloosterman, E., Van Oosten, H., Kumar, L. and Janssen, J. 2004. Mapping coastal vegetation using an expert system and hyperspectral imagery. Photogrammetric Engineering and Remote Sensing, 70(6): 703-716.

Somodi, I., Čarni, A., Ribeiro, D. and Podobnikar, T. 2012. Recognition of the invasive species Robinia pseudacacia from combined remote sensing and GIS sources. Biological Conservation, 150(1): 59-67.

Tuanmu, M. N., Viña, A., Bearer, S., Xu, W., Ouyang, Z., Zhang, H. and Liu, J. 2010. Mapping understory vegetation using phenological characteristics derived from remotely sensed data. Remote Sensing of Environment, 114(8): 1833-1844.

Ustin, S. L., DiPietro, D., Olmstead, K., Underwood, E. and Scheer, G. J. 2002. Hyperspectral remote sensing for invasive species detection and mapping. IEEE Geoscience and Remote Sensing Symposium, 3: $1658-1660$. 
Vaiphasa, C., Skidmore, A. K. and de Boer, W. F. 2006. A post-classifier for mangrove mapping using ecological data. ISPRS Journal of Photogrammetry and Remote Sensing, 61(1): 1-10.

van den Bosch, E., Ward, B. and Clarkson, B. 2004. Woolly nightshade (solanum mauritianum) and its allelopathic effects on new zealand native hebe stricta seed germination. New Zealand Plant Protection, 57: 98.

van Wilgen, B. W., Forsyth, G. G., Le Maitre, D. C., Wannenburgh, A., Kotzé, J. D. F., van den Berg, E. and Henderson, L. 2012. An assessment of the effectiveness of a large, national-scale invasive alien plant control strategy in South Africa. Biological Conservation, 148(1): 28-38.

van Wilgen, B. W., Reyers, B., Le Maitre, D. C., Richardson, D. M. and Schonegevel, L. 2008. A biome-scale assessment of the impact of invasive alien plants on ecosystem services in South Africa. Journal of Environmental Management, 89(4): 336-349.

van Wilgen, B. W., Richardson, D. M., Le Maitre, D. C., Marais, C. and Magadlela, D. 2001. The economic consequences of alien plant invasions: Examples of impacts and approaches to sustainable management in South Africa. Environment, Development and Sustainability, 3(2): 145-168.

Wang, T., Skidmore, A. and Toxopeus, A. 2009. Improved understorey bamboo cover mapping using a novel hybrid neural network and expert system. International Journal of Remote Sensing, 30(4): 965-981.

Wilfong, B. N., Gorchov, D. L. and Henry, M. C. 2009. Detecting an invasive shrub in deciduous forest understories using remote sensing. Weed Science, 57(5): 512-520.

Williams, A. P. and Hunt, R. 2002. Estimation of Leafy spurge cover from hyperspectral imagery using mixture tuned matched filtering. Remote Sensing of Environment, 82(2): 446-456.

Witkowski, E. T. F. and Garner, R. D. 2008. Seed production, seed bank dynamics, resprouting and long-term response to clearing of the alien invasive solanum mauritianum in a temperate to subtropical riparian ecosystem. South African Journal of Botany, 74(3): 476-484. 